\title{
Intense Rainfall in São Carlos/SP: Determination of Threshold Values Using Climate Indices and Their Spatio-Temporal Repercussion
}

\author{
Rafael Grecco Sanches ${ }^{1}$, Gustavo Zen de Figueiredo Neves' ${ }^{1}$, Bruno Cesar dos Santos' \\ Maurício Sanches Duarte Silva', Diego Narciso Buarque Pereira1, \\ Adriano Rogério Bruno Tech ${ }^{2}$
}

\author{
${ }^{1}$ São Carlos School of Engineering, University of São Paulo (USP), São Paulo, Brazil \\ ${ }^{2}$ Department of Animal Science and Food Engineering, University of São Paulo \\ (USP), São Paulo, Brazil \\ Email: rafagsanches@usp.br
}

How to cite this paper: Sanches, R.G., de Figueiredo Neves, G.Z., dos Santos, B.C., Silva, M.S.D., Pereira, D.N.B. and Tech, A.R.B. (2018) Intense Rainfall in São Carlos/SP: Determination of Threshold Values Using Climate Indices and Their Spatio-Temporal Repercussion. American Journal of Climate Change, 7, 388-401. https://doi.org/10.4236/ajcc.2018.73023

Received: May 14, 2018

Accepted: August 14, 2018

Published: August 17, 2018

Copyright $\odot 2018$ by authors and Scientific Research Publishing Inc. This work is licensed under the Creative Commons Attribution International License (CC BY 4.0).

http://creativecommons.org/licenses/by/4.0/

\begin{abstract}
The intense and extreme rains in southeastern Brazil are spatially and temporally dynamic, corroborating their substantial complexity regarding understanding and associations. Therefore, the present study aimed at determining threshold values for events of intense and extreme rainfall in the region of São Carlos/SP using a climatic index, as well as temporal and spatial observations. The RClimdex script, Rnn index, and the detection of outliers were employed in order to mark and establish intense and extreme rainfall thresholds for the region. Values of $10 \mathrm{~mm}$ and $20 \mathrm{~mm}$ of rain were considered typical and of greater recurrence, and their incidence over a period of 24 hours did not necessarily denote intense events. In turn, values of 35, 46, and $60 \mathrm{~mm}$ indicate pluviometric rates that impact on significant disasters, as verified in the IPMET/UNESP natural disasters database. It is important to emphasize that values below $60 \mathrm{~mm}$ of daily rainfall may also indicate disaster contexts. However, they do not exclude the necessity to verify the intensity, duration, and frequency of intense rain events, and can delineate thresholds for territorial management organizations in their planning.
\end{abstract}

\section{Keywords}

Climatology, Tropical Climatology, Statistical Climatology, Intense Raining, Extreme Events 


\section{Introduction}

The rains of the Brazilian southeast are seasonal and occur predominantly during the summer (DJF-December/January/February). Rainfall events in the region are mainly associated with active frontal systems (FS) in the area and complex regional atmospheric movements at different scales.

According to some studies [1], positive trends regarding local variations in rainfall patterns are noteworthy in southeastern Brazil, and are associated with the SACZ (South Atlantic Convergence Zone), accelerated urbanization, soil usage, and dynamic and thermodynamic mechanisms, among other factors.

The frontal systems that influence the southeastern region of the country are, in turn, associated with convection and, therefore, can promote large accumulated rainfall values depending on the displacement speed of these systems [2].

One of the ways to verify the occurrence of an episode of intense rain is by measuring the frequency of its distribution. In the southeast, the highest frequency range of rainy days exceeds $40 \%$ of that value [2].

In order to determine the distribution frequency, an episode of intense rain can be expressed by means of an average value (in the month of its occurrence, for example), in a set of seasons, that exceeds the quantile in 99\% [2].

Furthermore, it is noteworthy that extreme and/or intense episodes are associated, among other aspects, with socio-environmental effects. The number of fatalities, economic and health damages, and other impacts, which explain the high vulnerability of the population, are related to events such as intense or prolonged rains [3].

Urban occupation, in addition to the occurrence of intense rain phenomena, potentiates local and regional impacts, represents different responses of these events in a given geographic area.

In view of the problems and the bias of intense rains, the present study proposed the analysis of data regarding intense rainfall using climatic indices in the region of São Carlos/SP.

\section{Materials and Methods}

\section{Determination of Intense Rainfall}

Extreme values of rainfall represent one of the most prominent aspects of current climatological studies, given they are associated with floods, landslides, and agricultural crop losses, among other impacts, near rural and urban areas. Thus, the detection of extreme values and their interannual behavior can contribute to planning in different decision-making spheres, as well as comprise a valid method for such observation.

In order to determine intense rain events, distinct criteria, such as fixed values regarding extreme rainfall ( $60 \mathrm{~mm}$ in a single day), are noted [4]. However, the occurrence of rainfall above this value may not necessarily represent the local climatic reality. In the studied region, the determination of extreme rainfall values was different from the average attributed value on the regional scale (i.e., the 
state of São Paulo).

Some studies indicate that extreme rainfall values may be associated with their intensity [5], as determined by the World Meteorological Organization (WMO), expressed in Table 1.

Another classification employed in the identification of extreme rainfall in the region corresponds to the association between intense rainfall events and the South Atlantic Convergence Zone (SACZ) phenomenon, which indicates the use of teleconnections for such determination [6].

Thus, it can be emphasized that, during the rainy season, the occurrence of the SACZ increases the possibility of intense rainfall. Nonetheless, it does not exclude the incidence of rainfall extremes during the dry season and the transition period, given these parameters convey the seasonal dynamics of rainfall in the Brazilian southeast [6] [7].

The present study was conducted using databases that corresponded to the following weather stations: the Center for Water Resources and Environmental Studies (CRHEA), located in the municipality of Itirapina, pertaining to the São Carlos School of Engineering of the University of São Paulo; the station of the National Institute of Meteorology (INMET), located at the Federal University of São Carlos, and the station of the Brazilian Company of Agricultural Research-Pecuária Sudeste (EMBRAPA); all of which are positioned in the São Carlos/SP region, as shown in Figure 1 and Table 2.

The data were utilized in the southeastern region of South America [8], in which $60 \mathrm{~mm}$ or more of rainfall was expected to occur at least two days per year. In some years, these events took place during four days, while, in others, events with rain above this amount were not observed. Their occurrence was also verified in December, January, and February, rendering the admission of this value as a reference for extreme days of rainfall more complex.

The R software and RClimdex script [10] were employed in the statistical treatment and data analysis using the climate indices [11] [12]. In the present study, the rainfall index was determined according to Table 3.

The software was developed by Byron Gleason of the National Climate Data Center (NCDC) of the National Oceanic and Atmospheric Administration (NOAA), and its use has been detailed at several workshops and meetings of the CCI/CLIVAR (International Research Programme on Climate Variability and Predictability) on climatic elementsand their variability, since 2001. It consists of

Table 1. WMO determination of intense rains.

\begin{tabular}{ccc}
\hline Rain classification & Rainfall $(\mathrm{mm})$ & Occurrence/Duration (minutes/hour) \\
\hline Light & up to 0.8 in 10 minutes & from 1.1 to $5.1 /$ hour \\
Moderate & up to 4.0 in 10 minutes & from 5.1 to $25.0 /$ hour \\
Heavy & up to 8.0 in 10 minutes & from 25.1 to $50.0 /$ hour \\
Intense & over 8.0 in 10 minutes & more than $50.0 /$ hour
\end{tabular}

Source: [5]. 
Table 2. Weather stations utilized in the study.

\begin{tabular}{ccccc}
\hline Station & Altitude & Latitude & Longitude & Operation \\
\hline CRHEA & 737 & $22^{\circ} 10^{\prime} 12^{\prime \prime}$ & $47^{\circ} 53^{\prime} 55^{\prime \prime}$ & 1972 -present day \\
INMET & 856 & $21^{\circ} 48^{\prime} 58^{\prime \prime}$ & $47^{\circ} 53^{\prime} 02^{\prime \prime}$ & 1939 -present day \\
EMBRAPA & 850 & $21^{\circ} 09^{\prime} 00^{\prime \prime}$ & $47^{\circ} 08^{\prime} 00^{\prime \prime}$ & 1992 -present day \\
\hline
\end{tabular}

Table 3. Climate index interpreted by the RClimdex.

\begin{tabular}{cccc}
\hline Index & Name & Definition & Unit \\
\hline Rnn & $\begin{array}{c}\text { Rainy days with over } \\
\text { nn millimeters }\end{array}$ & $\begin{array}{c}\text { Number of days with over } \\
\text { nn millimeters of rain }\end{array}$ & Days \\
\hline
\end{tabular}

$\mathrm{RR} \mathrm{jj}$ is adopted as the daily amount of precipitation in day $\mathrm{i}_{\mathrm{i}}$ in a period. Thus, $\mathrm{nn}^{*}$ represents any reasonable amount of daily precipitation, where the number of days is summed, in which: $R R j j \geq \mathrm{nnmm}$.

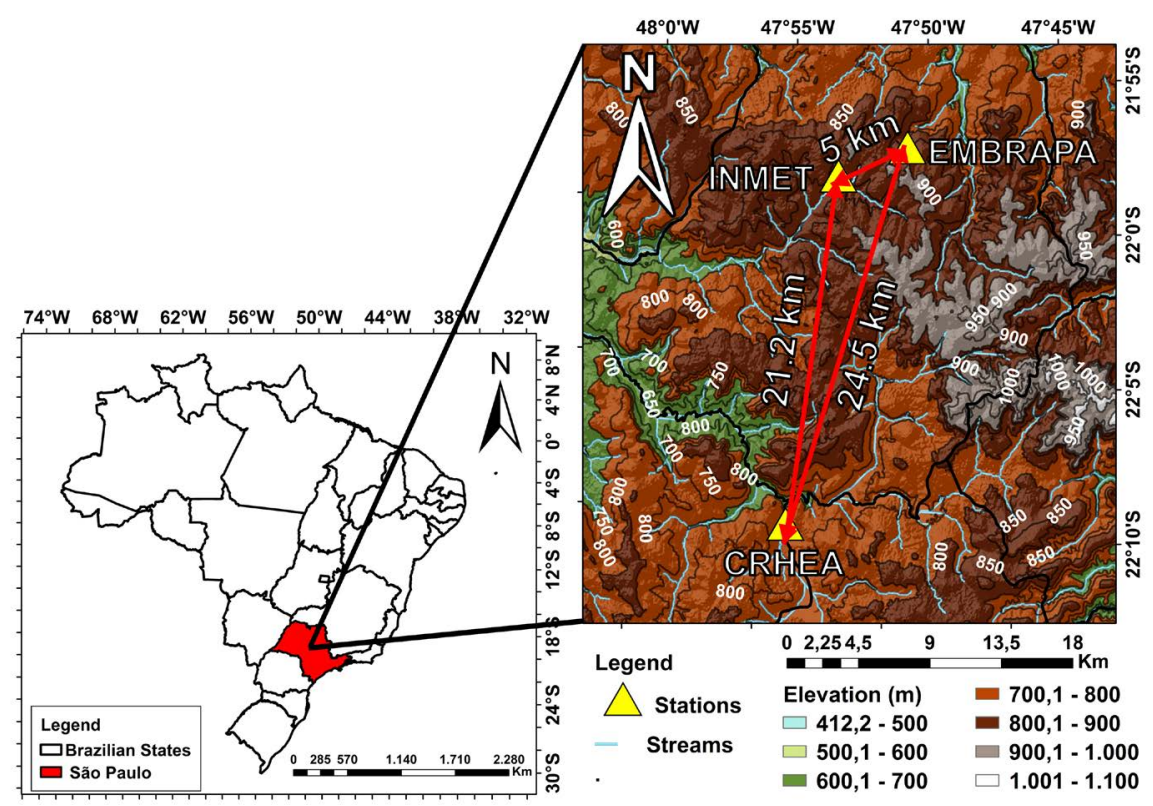

Figure 1. Location of the weather stations. Adapted [9].

an environment and a language for statistical and graphical computing. Given the software is considered a GNU Project, it represents the creation of an operating in na open source system set which is similar to the language and environment of the $\mathrm{S}$ software, developed in Bell laboratories (former AT\&T, now known as Lucent Technologies) by John Chamberg and colleagues.

The $\mathrm{R}$ software provides a wide variety of linear and non-linear modeling, classical statistical tests, time-series analysis, classification, and clustering, among other statistical and graphical techniques, as well as an open source route for participation in this activity. Its use together with climate changes may represent an advance in the interpretation of climatological data, given the software utilizes daily data in its analysis and index calculation.

The RClimdex script calculates 27 basic indices recommended by the ETCCDMI (Climate Change Detection Monitoring Indices) for temperature and 
precipitation. In the present study, only the Rnn index was employed to determine the number of days with more than ${ }^{*}$ nn millimeters of rain, a value which was entered by the user.

The data quality control was performed by replacing all the missing data with -99.9 (recognized as "missing" by the script). Some further information data were verified, the most critical occurring in the year 1994, which exceeded 5\%.

The data entry format was annual, that is, the first day of January of the first year of the adopted historical series, followed by the respective rainfall value, until the last day of December of the last year of the adopted historical series, accounted for 365 days (and rainfall data) and 366 days in leap years (January-December).

One of the indices that enable the best visibility regarding rainfall variation in the weather stations is Rnn, which represents the number of days with precipitation values above a user-determined amount, that is, a baseline or reference value can be attributed to what is considered extreme, along with rainfall values. Accordingly, one of the most significant aspects for its understanding was the attribution and detection of outliers, which consist of values considered anomalous in the historical series, and that, in the present study, corresponded to a method of observation of extensive sets of data for the determination of extreme rainfall values.

The Rnn index results in the number of days with more than ${ }^{\star} n n$ millimeters of rain, annually, in each observed season.

In this study, the determination of the nn value was carried out after outlier detection (abnormal observations), which, in turn, represent a fact that diverts considerably from others to the point of generating suspicion that it was produced by a different mechanism, that is, they configure unusual or exceptional values found in the dataset [13].

Outlier determination can be understood as an evaluation, which, in this sense, consists of studying the evolution and identification of exceptional behaviors in a data series. Since an outlier is considered a manifestation of exceptional properties, it is commonly identified using a mean with three or four standard deviations (+/-) per boundary [14].

The anomalous behavior in the data series, that is, the average values considered exceptional and that do not correspond to the mean values detected in the whole set of data, can be observed using the equation below. The outliers were used in order to establish the rainfall limits for the historical series using Equation (1):

$$
\frac{\sum_{i=1}^{\mathrm{n}} x_{i}}{\mathrm{n}}+3(\text { or } 4) \cdot \sqrt{\frac{\sum x^{2}-\left(\sum x\right)^{2} / \mathrm{n}}{\mathrm{n}}}=\text { Outlier(Standard observation) }
$$

The exit data were analyzed together using temporal series graphs to interpret the behavior of the number of rainy days with $10,20,35,46$, and $60 \mathrm{~mm}$ of precipitation. 


\section{Results}

The values considered recurrent in all of the rainy periods, as well as in all the years of the historical series, were selected (10 $\mathrm{mm}$ and $20 \mathrm{~mm}$ of rainfall). Additionally, values of $35 \mathrm{~mm}$ and $46 \mathrm{~mm}$ of rain were calculated by the determination of intense rainfall, and of $60 \mathrm{~mm}$, since this value is considered the intense rain threshold, as previously mentioned, for the assessed region.

Values of $35 \mathrm{~mm}$ and $46 \mathrm{~mm}$ were identified as outliers in the historical series, and were considered rainfall extremes by the weather stations. Interannual fluctuations can be noted in both indices, with significant seasonal variations over the last five years. Moreover, extreme rainfall was observed in some years, while in others, it was absent.

\subsection{Rnn mm (Number of Days with More than nn* Millimeters of Rainfall)}

The data concerning the Rnnmm index correspond to the determinations of rainfall values, in millimeters, calculated according to the operator's choice. Using these data, researchers can understand the behavior of rainfall events by adopting a given amount of millimeters, which comprise the basis for such calculation.

The R10 and R20 indices were calculated using the data from the weather stations, and were compared with other results [15], the latter being discrepant regarding the present report, in which an increase in two days with above $10 \mathrm{~mm}$ and $20 \mathrm{~mm}$ of rain was verified in the decades between 1951 and 2010 . However, a decrease in these values was observed in the last years, especially in 2014, when the lowest values of the whole historical series were recorded (Figure 2 and Figure 3).

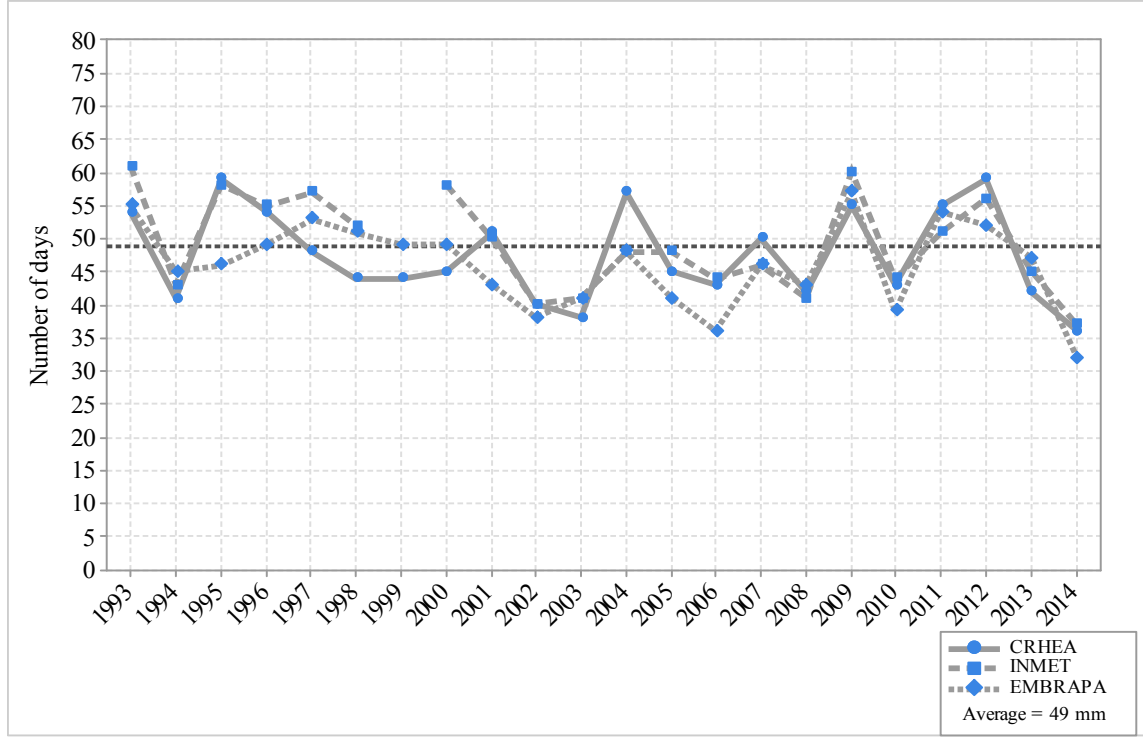

Figure 2. R10 mm-Number of days in which the daily rainfall surpassed $10 \mathrm{~mm}$ at the weather stations (1993-2014). 


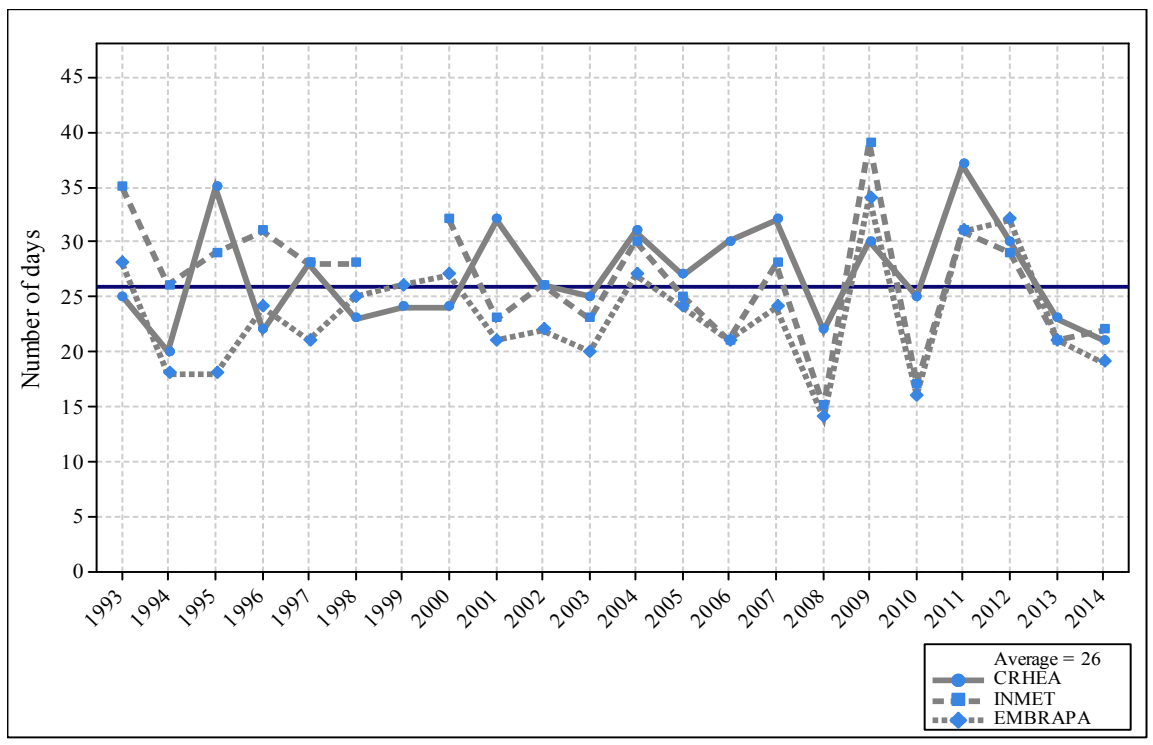

Figure 3. R20 mm-Number of days in which the daily rainfall surpassed $20 \mathrm{~mm}$ at the weather stations (1993-2014).

The R20 $\mathrm{mm}$ and $\mathrm{R} 60 \mathrm{~mm}$ indices were adopted and, using the abnormal observation calculation (outlier detection), rainfall above $35 \mathrm{~mm}$ and $46 \mathrm{~mm}$ corresponded to extreme rain events at the CRHEA, INMET/UFSCar, and EMBRAPA stations. Rains above $20 \mathrm{~mm}$ were selected due to their observable occurrence in all the years of the historical series. Rainfall above $35 \mathrm{~mm}$ and $46 \mathrm{~mm}$ corresponded to the abnormal data observations and were considered as base values for the determination of exceptional or extreme rains. In turn, precipitation above 60 $\mathrm{mm}$ was calculated in order to understand the behavior of the days that exhibited higher volumes of rainfall, in accordance with Lima and Amorim (2015) [4].

According to the number of days with rainfall above ${ }^{\star}$ nn millimeters and their malleability, this index is considered as plausible for the temporal analysis of annual rains, as an understanding of larger, smaller, or similar amounts regarding the quantity of extreme rainfall that occurred and/or that was previously expected for a given year, in addition to adapting to any analyzed climatic reality.

\subsection{R35 mm (Number of Days with More than 35 Millimeters of Rainfall)}

The calculation of this index corresponds to the existence of outliers in the historical series of data, representing the incidence of exceptional rainfall, that is, to assess the behavior of rains considered atypical regarding the daily precipitation at the stations.

After determining the values considered abnormal observations for the series, those greater than $35 \mathrm{~mm}$ of rain were calculated by the index and expressed in Figure 4.

Considering the estimated data, it is possible to verify the existence of nine years in which the three weather stations showed similar behavior in daily rain 


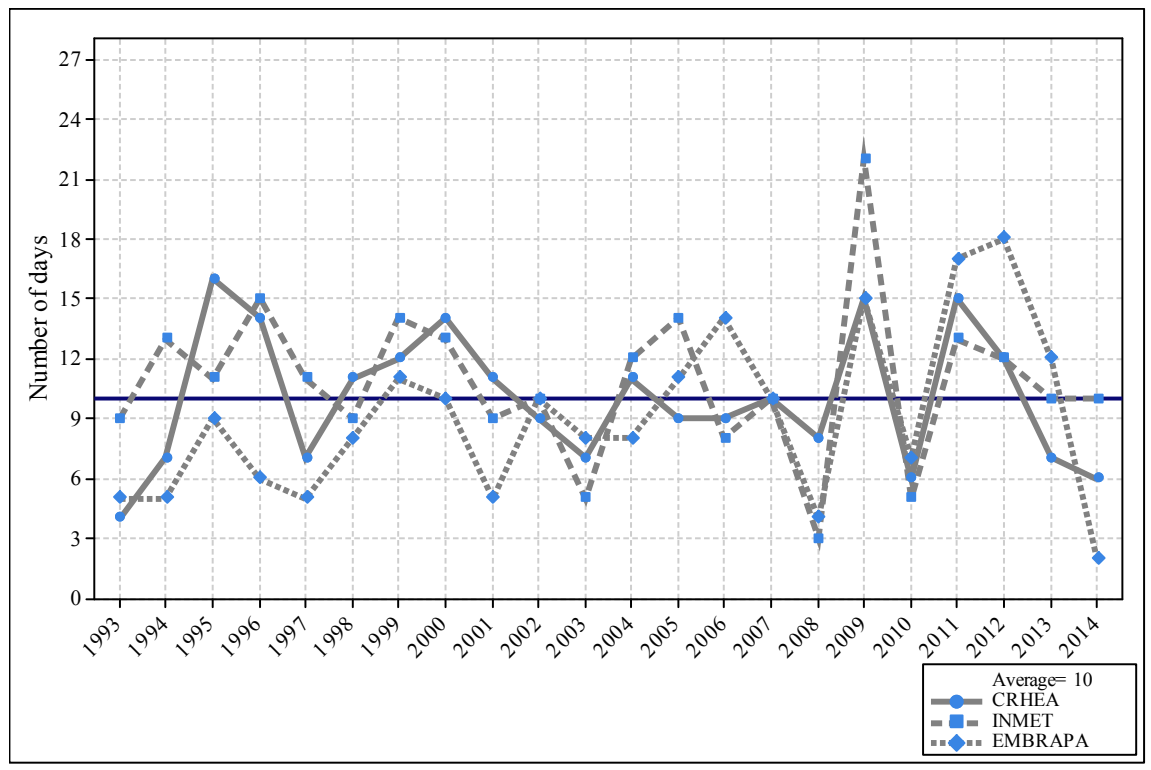

Figure 4. R35 mm-Number of days in which the daily rainfall surpassed $35 \mathrm{~mm}$ at the stations (1993-2014).

data records. From the reports, it can be observed that annual fluctuations occurred on the days when the rainfall was above $35 \mathrm{~mm}$, the last six years being those in which the oscillations above and below the obtained average (ten days) in the historical series were more remarkable.

In addition to the exceptional values observed in those years, another important factor was that, in 2014, the number of days in which rainfall was above $35 \mathrm{~mm}$, considered an abnormal observation value, was the lowest recorded in all of the historical series at the stations. The EMBRAPA weather station registered only three days with more than $35 \mathrm{~mm}$ of rain, while the other two reported six days in which this value was recorded.

According to the obtained data, it can be noted that 2009 was the year when all the stations showed at least 15 days in which rainfall surpassed $35 \mathrm{~mm}$. The INMET station recorded 22 days with rain above of this value, representing the highest amount of precipitation among the weather stations.

In order to interpret the values that were considered exceptional (abnormal observations in the historical series), the number of days in which rainfall was above $46 \mathrm{~mm}$ was also calculated.

\subsection{R46 mm (Number of Days with More than 46 Millimeters of Rainfall)}

The values considered exceptional regarding rainfall in the historical series were also estimated, adopting the detection of outliers as abnormal observations. To do so, $46 \mathrm{~mm}$ of rain was considered as the base value, and the days that exhibited higher amounts were represented annually from daily data. The number of days with more than $46 \mathrm{~mm}$ of rain in the historical series between 1993 and 2014 is shown in Figure 5. 


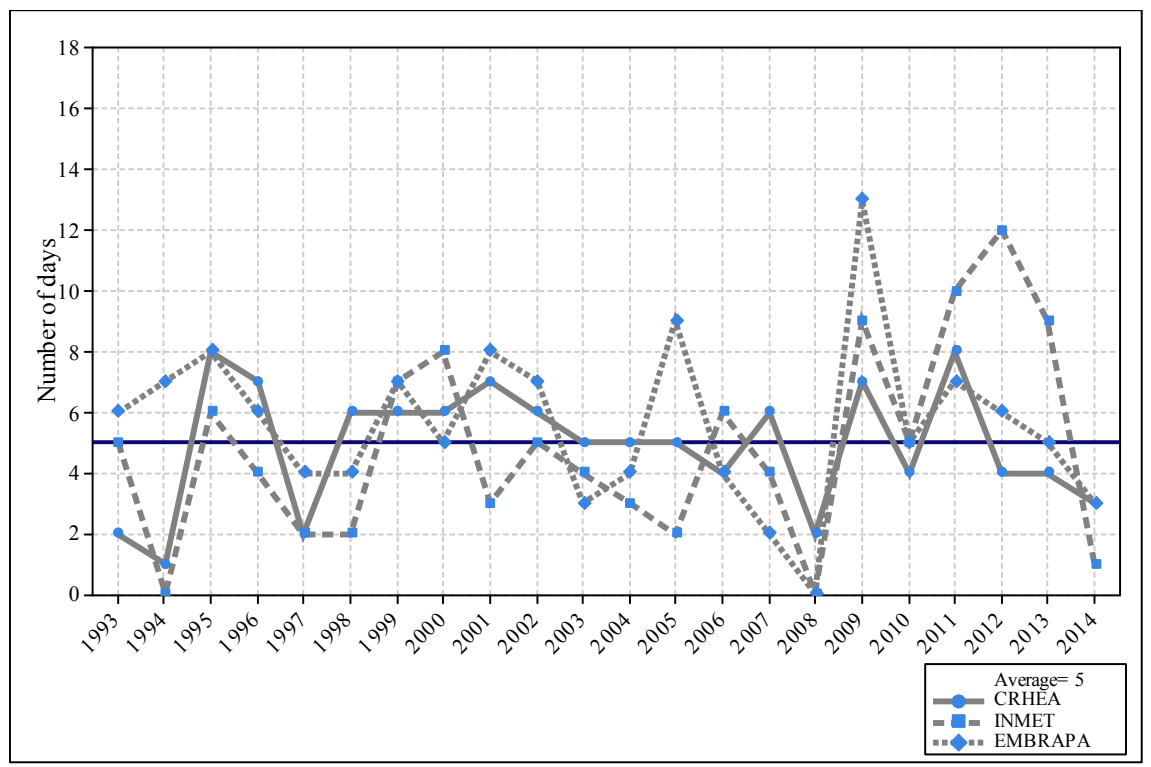

Figure 5. R46 mm-Number of days in which the daily rainfall surpassed $46 \mathrm{~mm}$ at the stations (1993-2014).

The rainy days that were considered exceptional in the historical series (more than $46 \mathrm{~mm}$ of precipitation) showed significant data fluctuations. During the period, the average number of 5 annual days with rainfall above this volume was adopted.

From the data, it was also verified that the greatest number of days with rainfall above $46 \mathrm{~mm}$ occurred during the last 6 years, despite the differences in data between the weather stations.

In 1994 and 2008, there were no records of any day with more than $46 \mathrm{~mm}$ of rainfall in two of the stations, the CRHEA being the only one that reported at least one rainy day that exceeded this amount.

According to the data analysis, it can be noted that the rains considered exceptional for the adopted historical series showed considerable variability between the stations. Also, the CRHEA station recorded at least one day every year with exceptional rainfall, and, in all seasons, these rains occurred, in spite of the fluctuations that took place over time.

\subsection{R60 mm (Number of Days with More than 60 Millimeters of Rainfall)}

Rainfall above $60 \mathrm{~mm}$ represents the last calculated index, together with the exceptionalities (abnormal observations) observed in the historical series. The number of days in which the daily rainfall exceeded $60 \mathrm{~mm}$ between 1993 and 2014 is shown in Figure 6.

After calculating the number of days with more than $60 \mathrm{~mm}$ of precipitation in the stations, significant data fluctuations for the period were observed, as well as the existence of disparities between the stations regarding the performed measurements. 


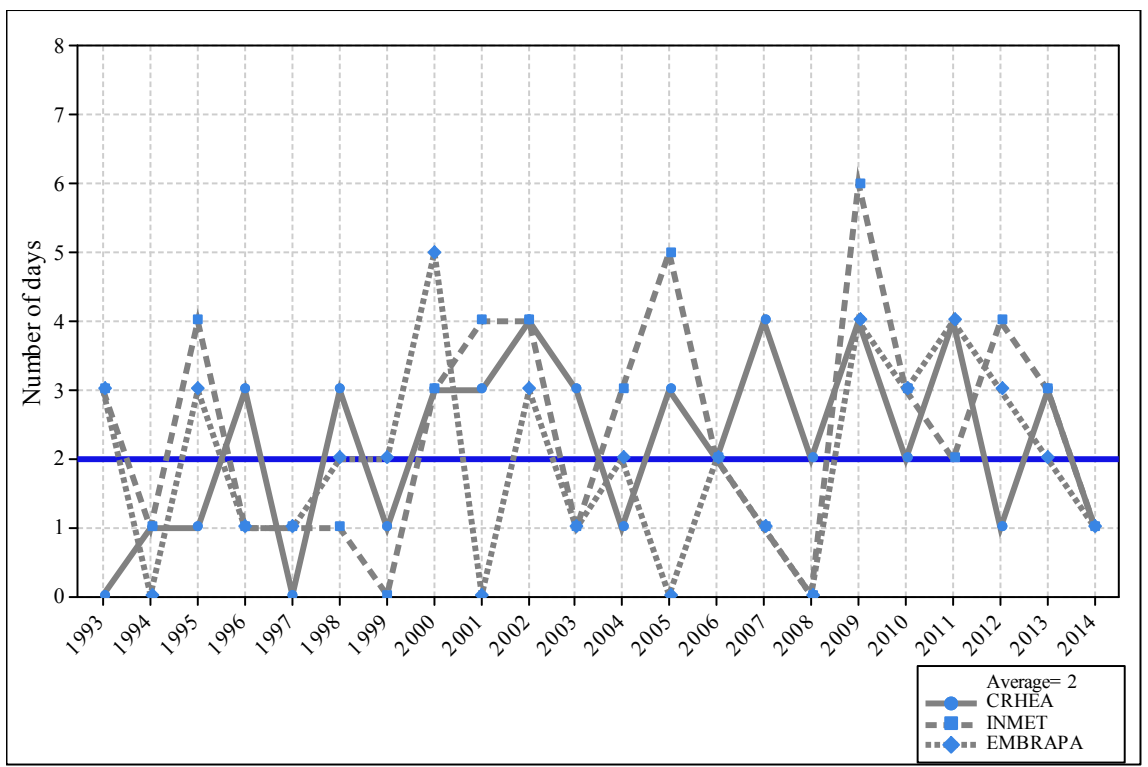

Figure 6. R60mm-Number of days in which the daily rainfall surpassed $60 \mathrm{~mm}$ at the stations (1993-2014).

Precipitation above $60 \mathrm{~mm}$ also represents abnormal observations or exceptionalities over an analyzed period. Among the main aspects is the seasonal and inter-annual variation in data. In 1993 and 1997, the CRHEA station did not register any day in which the rains exceeded $60 \mathrm{~mm}$, although it recorded the highest number of years with rainfall above $60 \mathrm{~mm}$ between the analyzed stations when compared with the average of 2 days, which corresponds to the average number of annually expected days in the weather stations.

The EMBRAPA and INMET weather stations showed significant inter-annual fluctuations, which does not characterize a tendency to increase or decrease the number of days with rainfall over $60 \mathrm{~mm}$. In 2014, the last year calculated by the index, all of the stations registered only one day with more than $60 \mathrm{~mm}$ of precipitation.

\subsection{Spatio-Temporal Repercussions of the Extreme Phenomena}

The repercussion of intense rainfall values in space is remarkable. The detection of the threshold value for its occurrence can contribute directly to planning, since, in episodes where rainfall (in 24 hours or less) adds to values of $46 \mathrm{~mm}$, problems regarding urban floods, significant regional material and social damage, as well as a series of rain events, can be observed. These occurrences cause damage to urban areas, as registered in the database of the Integrated Monitoring, Prevision, and Storm Alert System for the South-Southeast Regions of Brazil, of the Meteorological Research Institute of the State University of São Paulo [16], shown in Table 4.

In Table 5, the code referring to occurrence is shown, given these events promote distinct spatial repercussions. 
Table 4. Social disasters associated with rainfall in the São Carlos-SP region.

\begin{tabular}{|c|c|c|c|c|c|c|}
\hline Date & Phenomenon & Duration & Occurrences (legend)* & $\mathrm{N}^{\circ}$ damage & $\mathrm{N}^{\circ}$ victims & Source \\
\hline $03 / 16 / 05$ & Heavy rain & -1 & 31,43 & -1 & -1 & $\mathrm{CD}$ \\
\hline $10 / 26 / 05$ & Heavy rain & $20 \mathrm{~min}$ & 33,36 & -1 & -1 & $\mathrm{CD}$ \\
\hline $10 / 28 / 05$ & Heavy rain & -1 & $25,32,35,37$ & -1 & -1 & $\mathrm{CD}$ \\
\hline $12 / 16 / 05$ & Heavy rain & $40 \mathrm{~min}$ & $25,26,34,35,44$ & -1 & -1 & $\mathrm{CD}$ \\
\hline $12 / 21 / 05$ & Heavy rain & $2 \mathrm{~h}$ & $20,21,27,28,30,33,37$ & -1 & -1 & $\mathrm{CD}$ \\
\hline $02 / 14 / 06$ & Heavy rain & $1 \mathrm{~h}$ & $21,30,33$ & -1 & -1 & $\mathrm{CD}$ \\
\hline 01/09/09 & $\begin{array}{l}\text { Heavy rain/Strong } \\
\text { winds }\end{array}$ & -1 & $25,28,30,33,36(6), 37$ & 6 & -1 & $\mathrm{CD}$ \\
\hline $10 / 12 / 09$ & Continuous rain & -1 & $25(5), 37,53$ & 5 & -1 & $\mathrm{CD}$ \\
\hline $10 / 26 / 09$ & Heavy rain & -1 & $30,32,33,46$ & -1 & -1 & CD, FSP \\
\hline $12 / 17 / 09$ & Heavy rain & $1 \mathrm{~h}$ & $21(4), 25(1), 37$ & 5 & 4 & $\mathrm{CD}$ \\
\hline $10 / 07 / 10$ & Heavy rain & -1 & $33,37,52$ & -1 & -1 & G1 \\
\hline $01 / 31 / 11$ & Heavy rain & -1 & $29,30,33,35,37,46$ & -1 & -1 & G1 \\
\hline $02 / 26 / 11$ & Continuous rain & -1 & $23(1), 26,27,39,45$ & 1 & 1 & $\mathrm{CD}$ \\
\hline $02 / 26 / 11$ & $\begin{array}{l}\text { Continuous rain/ } \\
\text { Cyclone }\end{array}$ & -1 & $22(1), 23(1), 26,27,35,45$ & 2 & 2 & $\mathrm{CD}$ \\
\hline $02 / 27 / 12$ & Heavy rain & $15 \mathrm{~min}(16 \mathrm{~mm})$ & $28,29,30$ & -1 & -1 & G1 \\
\hline $06 / 05 / 12$ & Heavy rain & -1 & $28,32,33$ & -1 & -1 & G1 \\
\hline $10 / 23 / 12$ & Heavy rain & short duration & $25(10)$ & 10 & -1 & $\mathrm{CD}$ \\
\hline $10 / 23 / 12$ & Heavy rain & short duration & $25(10)$ & 10 & -1 & $\mathrm{CD}$ \\
\hline $11 / 09 / 12$ & Heavy rain & -1 & $25(3), 36(1), 37,40(1), 53(1)$ & 6 & -1 & G1 \\
\hline $12 / 09 / 12$ & Heavy rain & $10 \mathrm{~min}$ & $22(22), 25$ & 22 & 22 & $\mathrm{CD}$ \\
\hline $01 / 12 / 13$ & Continuous rain & Long duration & $27,34,39,46$ & -1 & -1 & $\mathrm{CD}$ \\
\hline $02 / 22 / 13$ & Heavy rain & $40 \mathrm{~min}$ & $26,28,30,32,34$ & -1 & -1 & $\mathrm{CD}$ \\
\hline 09/03/13 & Heavy rain & Short duration & $25,26,28,30,33,37$ & -1 & -1 & $\mathrm{CD}$ \\
\hline $05 / 28 / 13$ & Heavy rain & Short duration & $20(3), 25,30,33,34,41,46$ & 3 & 3 & $\mathrm{CD}$ \\
\hline $10 / 22 / 13$ & Heavy rain & Short duration & $\begin{array}{c}26,28,30,33(50), 34,35(5), 44, \\
46,56,57\end{array}$ & 55 & -1 & $\mathrm{CD}$ \\
\hline $11 / 04 / 13$ & Heavy rain & Short duration & 30 & -1 & -1 & G1 \\
\hline $11 / 30 / 13$ & Heavy rain & $30 \mathrm{~min}$ & $25,34,37$ & -1 & -1 & G1 \\
\hline $12 / 05 / 13$ & Heavy rain & Short duration & 25,34 & -1 & -1 & G1 \\
\hline $01 / 14 / 14$ & Heavy rain & Short duration & $21(5), 28,30,36(2), 37$ & 7 & 5 & $\mathrm{CD}$ \\
\hline 09/02/14 & Heavy rain & $2 \mathrm{~h}$ & $25(6), 28,30,33,36,37,56$ & 6 & -1 & G1 \\
\hline $11 / 09 / 14$ & Heavy rain & short duration & $25,30,34,36,40,53$ & -1 & -1 & $\mathrm{CD}$ \\
\hline $01 / 07 / 15$ & $\begin{array}{l}\text { Heavy rain/Strong } \\
\text { winds }\end{array}$ & short duration & $22(1), 23(1), 51$ & 2 & 2 & $\mathrm{CD}$ \\
\hline $11 / 23 / 15$ & Heavy rain & $30 \mathrm{~min}(58 \mathrm{~mm})$ & $28,30,32,33,34,35$ & -1 & -1 & $\mathrm{CD}, \mathrm{G} 1$ \\
\hline $01 / 25 / 16$ & Heavy rain & $1 \mathrm{~h} 30-32 \mathrm{~mm}$ & $28,33,34,39,46$ & -1 & -1 & G1 \\
\hline $03 / 23 / 16$ & Heavy rain & -1 & $25(40), 37$ & 40 & -1 & $\mathrm{CD}$ \\
\hline $05 / 16 / 16$ & Heavy rain & -1 & 20 (40), 25, 30, $33(80), 35,36,37$ & 120 & 40 & $\mathrm{CD}$ \\
\hline $06 / 01 / 16$ & Heavy rain & -1 & $20(16), 25(14), 33,35,36$ & 30 & 16 & $\mathrm{CD}$ \\
\hline $06 / 05 / 16$ & $\begin{array}{l}\text { Heavy rain/Strong } \\
\text { winds }\end{array}$ & $120 \mathrm{~km} / \mathrm{h}$ & $\begin{array}{c}21,22(2), 25,32,33,35,36(130) \\
37,40,53\end{array}$ & 132 & -1 & G1, SCA, CD \\
\hline $10 / 11 / 16$ & Heavy rain & -1 & $25,30,32(1), 33,37$ & 1 & -1 & $\mathrm{CD}$ \\
\hline
\end{tabular}

Observations: (CD) Civil Defense; (SCA) São Carlos Agora; (FSP) Folha de São Paulo. 
Table 5. Occurrence code/repercussion damage (disasters) legend.

\begin{tabular}{|c|c|c|c|}
\hline \multicolumn{4}{|c|}{ Description of the occurrence code/damage } \\
\hline Homeless & 20 & Lamppost collapsing & 40 \\
\hline Displaced & 21 & River margin collapsing & 41 \\
\hline Wounded & 22 & Airplane accident/Airport closing & 42 \\
\hline Fatal victim(s) & 23 & Hillside slippage & 43 \\
\hline Barrier collapsing & 24 & Car accident(s) & 44 \\
\hline Tree falling & 25 & Person dragged by flood & 45 \\
\hline River and stream overflow & 26 & Pavement damage & 46 \\
\hline Damage to bridges & 27 & Dam rupture & 47 \\
\hline Natural flooding & 28 & Water and sewer net rupture & 48 \\
\hline Inundation & 29 & Train accident & 49 \\
\hline Flooding & 30 & Indoor drowning & 50 \\
\hline Landslide & 31 & Lightning damage & 51 \\
\hline Wall collapsing & 32 & Tower collapsing & 52 \\
\hline Property collapsing/Cracking/Damage & 33 & Billboard collapsing & 53 \\
\hline Traffic jam/Public road interdiction & 34 & Coastal flooding & 54 \\
\hline Vehicle damage & 35 & Animals killed by lightning & 55 \\
\hline Roof damage & 36 & Floods & 56 \\
\hline Energy and water supply outage & 37 & Sudden flooding & 57 \\
\hline Crop and rural road destruction & 38 & Boat accident & 58 \\
\hline \multirow[t]{2}{*}{ Erosion/Hole(s) } & 39 & River silting & 59 \\
\hline & & & \\
\hline
\end{tabular}

Source: [16].

\section{Conclusions}

The calculation of the number of days with intense-and/or extreme-rainfall enables the insertion of threshold values for determination, using data from historical series of rainfall patterns. The data limitation in which the flaws do not impact on the calculation of such indices is present in the study and, thus, effective spatial observations can denote the problematic factors regarding this type of assessment.

Therefore, the different indices show significant dynamism in the interpretation of rainfall data in the São Carlos/SP region, allowing us to identify recurrent periods of extreme rainfall, now established based on data obtained from the area itself, without suppositions regarding its occurrence, and on the in situ identification of its behavior registered in the weather stations.

The $10 \mathrm{~mm}$ and $20 \mathrm{~mm}$ values varied in the historical series, and, thus, recurrence was noted in all of the analyzed years. Moreover, fluctuations in the number of days with such rainfall values are associated with years of more or less precipitation.

Thus, values of $35 \mathrm{~mm}$ and $46 \mathrm{~mm}$ represent the thresholds of intense and 
extreme rainfall for the study area, respectively, based on the data obtained in the weather stations.

In time, it is worth mentioning that, for all the values, the number of rainy days showed a significant decrease, as verified also in the volume of rain and its intensity [17].

According to this assumption, rainfall observations, due to their dynamism of occurrence in the temporal scale, can contribute to different areas of planning, such as in the agricultural and industrial sector, urban space, water supply, etc. When using reliable climatological data, that is, when data collection is performed in a controlled and adequate manner, and the understanding of its behavior is assessed by a tool that better interprets the climatologic data by way of a quantitative analysis, a structured planning process could be established, consequently supporting decision-making by political, economic, social, and environmental aspects, with viable theoretical-methodological framework.

The present study does not limit intense rainfall in single values to mark planning parameters, nor does it exclude the interaction with the intensity, duration, and frequency of intense and extreme rainfall events. However, it may provide new directions for the understanding of their prediction, given they are associated with disaster contexts.

In future studies, the need to reinforce the relationship between threshold values and the spatial repercussions associated with disasters is noteworthy. These qualitative and quantitative effects can be used to establish intense and extreme rainfall thresholds for the region.

\section{Acknowledgements}

The authors thank the Coordination for the Improvement of Higher Education Personnel (CAPES) and the National Council for Scientific and Technological Development (CNPq) for the financial support.

\section{Conflicts of Interest}

The authors declare no conflicts of interest regarding the publication of this paper.

\section{References}

[1] Zilli, M.T., Carvalho, L.M.V., Liebmann, B. and Silva Dias, M.A. (2017) A Comprehensive Analysis of Trends in Extreme Precipitation over Southeastern Coast of Brazil. International Journal of Climatology, 37, 2269-2279.

[2] Teixeira, M.S. and Satyamurty, P. (2011) Trends in the Frequency of Intense Precipitation Events in Southern and Southeastern Brazil during 1960-2004. Journal of Climate, 24, 1913-1921. https://doi.org/10.1175/2011JCLI3511.1

[3] Mendonça, F. and Leitão, S.A.M. (2009) Urban Socio-Environmental Risks and Vulnerability: A Perspective from the Water Resources. GeoTextos, 4, 145-163.

[4] Lima, A.P. and Amorim, M.C.C.T. (2015) Analysis of Episodes of Floods and Urban Floods in the City of São Carlos from Newspaper Reports. Journal Brazilian of 
Climatology, 15, 182-204.

[5] Oliveira, N., Fogaccia, C.V.C. and Almeida, R.M.B. (1998) Preliminary Characterization of Heavy Rains in the State of São Paulo. CBMET (Brazilian Congress of Meteorology-Anais), Brasília.

[6] Carvalho, L.M.V., Jones, C. and Liebmann, B. (2004) The South Atlantic Convergence Zone: Intensity, Form, Persistence, and Relationships with Intraseasonal to Interannual Activity and Extreme Rainfall. Journal of Climate, 17, 88-108.

[7] Zandonadi, L., Acquaotta, F., Fratianni, S. and Zavattini, J.A. (2016) Changes in Precipitation Extremes in Brazil (Paraná River Basin). Theoretical and Applied Climatology, 123, 741-756. https://doi.org/10.1007/s00704-015-1391-4

[8] Sanches, R.G. (2015) Rainfall Analysis in the São Carlos/SP Region: Understanding and Pluviometric Behavior from Climatological Stations, 1993-2014. M.Sc. Dissertation, São Carlos School of Engineering, University of São Paulo, São Paulo, 185 p.

[9] IBGE (2009) Instituto Brasileiro de Geografia e Estatística. Map of the State of São Paulo.

[10] Zhang, X. and Yang, F. (2004) RClimDex (1.0) User Guide. Climate Research Branch Environment Canada: Downsview, Ontario, Canada. http://etccdi.pacificclimate.org/software.shtml

[11] Haylock, M.R., et al. (2006) Trends in Total and Extreme South American Rainfall in 1960-2000 and Links with Sea Surface Temperature. Journal of Climate. 19, 1490-1512. https://doi.org/10.1175/JCLI3695.1

[12] Stephenson, T.S., Vincent, L.A., Allen, T., Van Meerbeeck, C.J., Mclean, N., Peterson, T.C. and Trotman, A.R. (2014) Changes in Extreme Temperature and Precipitation in the Caribbean Region, 1961-2010. International Journal of Climatology, 34, 2957-2971. https://doi.org/10.1002/joc.3889

[13] Hawkins, D. (1980) Identification of Outlier. Chapman and Hall, London. https://doi.org/10.1007/978-94-015-3994-4

[14] Chrun, D., Cukier, M. and Sneeringer, G. (2008) On the Use of Security Metrics Based on Intrusion Prevention System Event Data: An Empirical Analysis. 2008 11 th IEEE High Assurance Systems Engineering Symposium, Nanjing, 3-5 December 2008, 49-58. https://doi.org/10.1109/HASE.2008.52

[15] IPCC (2014) Climate Change 2014: Synthesis Report. In: Pachauri, R.K. and Meyer, L.A., Eds., Contribution of Working Groups I, II and III to the Fifth Assessment Report of the Intergovernmental Panel on Climate Change, Geneva, $151 \mathrm{p}$.

[16] UNESP (São PauloState University) Natural Disaster Database-Integrated System for Monitoring, Forecasting and Alert Storms for the South-Southeast Regions of Brazil (SIMPAT-SINAL-SOS/FINEP). http://www.ipmet.unesp.br/

[17] Sanches, R.G., Santos dos, B.C., Silva, M.S.D. and Vecchia, F.A.S. (2017) The Rains in the Region of São Carlos/SP: Analysis of Daily Maximum Values in the Historical Series, 1993-2014. Os Desafios da Geografia Física na Fronteira do Conhecimento, 1, 2280-2292. https://doi.org/10.20396/sbgfa.v1i2017.2589 